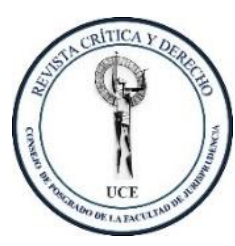

Crítica y Derecho

Revista Jurídica

e-ISSN 2737-6281 / p-ISSN 2737-629X

https://revistadigital.uce.edu.ec/index.php/criticayderecho/issue/view/297

Derecho, pandemia de la COVID-19 y sociedad

\title{
Las 200 millas de Mar Territorial y el Renunciamiento a la Tesis Soberana del Ecuador
}

The 200 nautical miles of territorial sea and the relinquishment of the Ecuadorian sovereign thesis

\section{Edgar Alonzo Coral Almeida}

Magister en derecho penal y derecho procesal penal.

Investigador Independiente. Ecuador.

Email: aloncoral@hotmail.com

ORCID: https://orcid.org/0000-0002-2949-8098

Guillermo Esteban Coral Robalino

Magister en derecho penal mención derecho procesal penal.

Investigador Independiente. Ecuador.

Email: guillermocoral7@gmail.com

ORCID: https://orcid.org/0000-0002-6277-4066

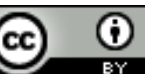

Crítica y Derecho: Revista Jurídica. Vol. 3(4), (enero-junio, 2022). pp. 57-67. 


\section{RESUMEN}

En esta investigación se analiza la evolución del derecho del mar en relación con la tesis ecuatoriana de las 200 millas de mar territorial, hasta la institucionalización de la Convención de las Naciones Unidas sobre el Derecho del Mar y la posterior adhesión del Ecuador a la referida Convención con las implicaciones jurídicas, políticas, económicas y de soberanía, se examinan los vicios jurídico-constitucionales en el proceso de aprobación de la CONVEMAR y los aspectos que lesionan la soberanía nacional e integridad territorial ante el renunciamiento a las 200 millas de mar territorial que el Ecuador venía sosteniendo como tesis nacional, lo cual, significa la mutilación de 188 millas de mar territorial y la cesión de la riqueza ictiológica alimentaria más significativa para el progreso y desarrollo ecuatoriano.

Palabras clave: derecho del mar, mar territorial, mar patrimonial, soberanía territorial, convención del mar, recursos naturales.

\section{ABSTRACT}

This research studies the evolution of the law of the sea in relation to the Ecuadorian thesis of the 200 miles of territorial sea, until the institutionalization of the United Nations Convention on the Law of the Sea, and the subsequent accession of Ecuador to the Convention with the legal, political, economic and sovereignty, it examines the constitutional legal defects in the approval process of the UNCLOS and the aspects that damage national sovereignty and territorial integrity before the renouncement of the 200 miles of territorial sea that Ecuador had been holding as a national thesis, which means the mutilation of 188 miles of territorial sea and the transfer of the most significant ichthyological food wealth for ecuadorian progress and development.

Keywords: Law of the sea, territorial sea, patrimonial sea, territorial sovereignty, convention of the seat, natural resources.

\section{INTRODUCCIÓN}

El Estado ecuatoriano se ha caracterizado por la defensa de un mar territorial de 200 millas náuticas, concebida como una zona adyacente al territorio del Estado costero, donde este ejerce soberanía y jurisdicción exclusiva, debiendo considerarse al mar territorial como una prolongación del territorio con las limitaciones establecidas por el Derecho Internacional, tesis que fuera asumida como una posición nacional, desde agosto de 1952, en que el Ecuador junto con Chile y Perú, hicieron uso del derecho a determinar su mar territorial en 200 millas náuticas, conforme a la Declaración de Santiago, posición que fuera reafirmada por el Ecuador en noviembre de 1966, al introducirse en los artículos 628 y 629 del Código Civil, "[...] el Mar Territorial Ecuatoriano hasta una distancia de 200 millas marinas", determinando de "[...] dominio nacional el espacio aéreo correspondiente al territorio del Estado, incluido en este el Mar territorial.", posición que fuera desarrollada por la diplomacia ecuatoriana en diversos foros internacionales sobre el derecho del mar y considerada como la antesala para que se adopte un régimen racionalizado del mar, que hasta entonces había sido patrimonio casi exclusivo de unas cuantas potencias, buscando evitar la presencia depredadora de naves extranjeras en las aguas territoriales de los Estados parte.

Resultado de los intereses económicos y políticos de las grandes potencias, en el mes de diciembre de 1970, la Asamblea General de las Naciones Unidas convoca 
a la III Conferencia sobre el Derecho del Mar, la misma que tuvo lugar en Nueva York, el treinta de diciembre de 1973, y luego de once períodos de sesiones, el primero en Caracas y, el último, en Jamaica, el 10 de diciembre de 1982, se aprueba la Convención sobre el Derecho del Mar (CONVEMAR), en Bahía Montego, Jamaica, y entra en vigencia el 16 de noviembre de 1994. La Convención aprueba que "Todo Estado tiene derecho a establecer la anchura de su mar territorial hasta un límite que no exceda de 12 millas marinas a partir de líneas de base determinadas de conformidad con esta Convención", siendo esta la razón para que el Ecuador no la suscribiera, ratificándose en la tesis de las 200 millas de mar territorial, como la única solución jurídicamente razonable para proteger sus riquezas ictiológicas y minerales de las grandes potencias depredadoras de los mares.

La tesis de la soberanía sobre las 200 millas de mar territorial, que significa jurisdicción en todas las materias, civil, penal, fiscal, tributaria, etc. y los derechos soberanos para la explotación de todos los recursos, entre ellos la pesca, gas, petróleo, minerales y energía, que en sus inicios fue ejercida por la diplomacia ecuatoriana, con valor, perseverancia y vasto conocimiento de la materia, finalmente fue abandonada por el gobierno de la "Revolución Ciudadana" en la presidencia de Rafael Vicente Correa Delgado, quien luego del dictamen favorable de la Corte Constitucional y la aprobación de la Asamblea Nacional, mediante Decreto Ejecutivo, ratificó la adhesión a la Convención de las Naciones Unidas sobre el Derecho del Mar (CONVEMAR)", con lo cual, el Ecuador pasa a ser miembro pleno de la Convención, renunciando a la tesis soberana de las doscientas millas de mar territorial y aceptando se vea reducida la soberanía marítima del Ecuador, en sus ámbitos continental e insular a un mar territorial ínfimo de doce millas marinas de conformidad a lo estatuido en el art. 3 de la Convención, lo que significa para el Ecuador la pérdida de 1'095.445 kilómetros cuadrados de mar territorial, lo que forma parte de una nefasta historia de desmembraciones del territorio nacional, de lo cual son responsables los grupos políticos que han gobernado el Ecuador, quienes a nombre del progreso y desarrollo nacional, falazmente han quebrantado los mandatos constitucionales, que determinan que "El territorio del Ecuador es inalienable, irreductible e inviolable.

\section{DESARROLLO}

\section{De la soberanía territorial del Ecuador}

El territorio es uno de los elementos esenciales para la existencia de una nación, lo habita una comunidad organizada, unida por raíces históricas y culturales, con órganos de gobierno propios, soberanos y políticamente independientes de otras comunidades, El territorio es el asiento material de una nación, en este se construye la vida de un pueblo, y en gran medida de ello depende su progreso y desarrollo; en este están las raíces materiales y espirituales que configuran el ideal de patria; consecuentemente, sin territorio no existe nación, patria, ni pueblo; por esto, es imperativo que en la Ley fundamental se describa el territorio, lugar donde el pueblo ejerce su soberanía, así:

La Constitución de 1821 también conocida como la Constitución de Cúcuta, tuvo como objeto la creación de la Gran Colombia, conformada por tres grandes departamentos: Cundinamarca, Venezuela y Quito, este último integrado por los departamentos de Ecuador con capital en Quito, de Azuay con capital en Cuenca, y de Guayaquil con capital en la ciudad de Guayaquil, estableciendo que el territorio de Colombia era el mismo que comprendían el antiguo Virreinato de la Nueva Granada y la Capitanía General de Venezuela. Disuelta la Gran Colombia, el distrito del Sur se 
proclama República independiente, y la Constitución fundacional de 1830, dispuso que los departamentos del Azuay, Guayas y Quito queden reunidos entre sí, formando un solo cuerpo independiente con el nombre de Ecuador, con los límites del antiguo Reino de Quito. La de 1835, determina que el territorio de la República del Ecuador comprende el de las provincias de Quito, Chimborazo, Imbabura, Guayaquil, Manabí, Cuenca, Loja y el Archipiélago de Galápagos. La de 1843, establece que el territorio de la República del Ecuador está compuesto de los distritos de Quito, Guayas y el Azuay y comprende todas las provincias del antiguo Reino y Presidencia de Quito, incluso el Archipiélago de Galápagos. La de 1845 se remonta al texto de la de 1835.

La de 1850, establece que la República del Ecuador comprende todo el territorio ecuatoriano, cuyos límites se fijarán definitivamente por tratados públicos con las naciones vecinas, teniendo en consideración sus derechos anteriores y presentes. Las constituciones de 1852, 1861, 1869, 1878, 1883, 1897, 1906 y 1929 se refieren al territorio de las provincias que formaron o con que se estableció la antigua Presidencia de Quito. La de 1945 sólo prescribe que el territorio del Ecuador, continental e insular, es inalienable e irreductible.

En las constituciones de 1979 y 1998 se instituye que el territorio ecuatoriano Comprende el de la Real Audiencia de Quito, con las modificaciones introducidas por los tratados válidos, las islas adyacentes, el Archipiélago de Galápagos, el mar territorial, el subsuelo y el espacio suprayacente respectivo, disponiendo que el territorio es inalienable e irreductible.

Cuando en el texto constitucional de 1998, art. 2, se hace constar que el territorio ecuatoriano comprende el de la Real Audiencia de Quito, "con las modificaciones introducidas por los tratados válidos [...]", implícitamente se desconoce el "Protocolo de Río de Janeiro", mal llamado de "Paz, Amistad y Límites" firmado en enero de 1942 por el presidente Carlos Alberto Arroyo del Río, impuesto por la fuerza de las armas por la República del Perú, y la intimidación y el chantaje de varios gobiernos del continente, conjugado con un gobierno de pusilánimes e inescrupulosos que traficaron con los más altos intereses nacionales, por lo que fue declarado oficialmente nulo el 17 agosto de 1960, en la presidencia de José María Velasco Ibarra, nulidad que se sustenta en el Derecho Público Americano que desde sus orígenes ha consignado principios fundamentales que proscriben el uso de las armas y la fuerza para resolver problemas y diferendos entre las naciones americanas e invalidan, los acuerdos firmados bajo estas condiciones, en que el protocolo de Río de Janeiro se consideraba inejecutable en una parte sustancial, toda vez que, el "divortium aquarium" entre el río Zamora y el río Santiago, establecido como límite en el artículo 8vo del Protocolo es inexistente; y que, existen normas internacionales, reconocidas por los propios gobiernos, para mantener la coexistencia pacífica entre países, por lo que, se consideraba que aceptar el Protocolo de Río de Janeiro, significaba aceptar la validez de todos los tratados firmados bajo la presión de las armas, reconocer el "derecho" de los países belicistas a anexionarse territorios, mediante el uso de la fuerza e invalidar y desconocer todas las normas del Derecho Internacional, los acuerdos y declaraciones que los confirman y el deseo de paz de las naciones que pugnan por un mundo donde impere la justicia, el progreso y el bienestar de los pueblos.

Por lo tanto, al 10 de diciembre del año 1982, fecha en que fue aprobada la CONVEMAR, conforme la Constitución de 1998, el Ecuador reivindicaba los siguientes límites: por el Norte, Colombia; por el Noreste, Costa Rica (por las Islas Galápagos o Archipiélago de Colón, límite marítimo); por el Sur y por el Este, Perú; y, por el occidente, el Océano Pacifico. A mil ciento veinte kilómetros del Ecuador 
continental se encuentra el archipiélago de Galápagos, y frente al perfil costanero se encuentran otras islas, entre las principales, la Isla Puná, Del Muerto, Santa Rosa, y La Tola. De tales límites se desprende que la superficie terrestre continental-insular del Ecuador correspondía aproximadamente a 584.000 kilómetros cuadrados de superficie.

En la Constitución de la República del Ecuador, publicada en el RO 449: 20-oct2008, artículo 4, inciso primero, se afirma que "[...] el territorio del Ecuador comprende el espacio continental y marítimo, las islas adyacentes, el mar territorial, el Archipiélago de Galápagos, el suelo, la plataforma submarina, el subsuelo y el espacio suprayacente continental, insular y marítimo. Sus límites son los determinados por los tratados vigentes [...]", para a continuación sancionar que: "[...] El territorio del Ecuador es inalienable, irreductible e inviolable.", y que, "Nadie atentará contra la unidad territorial ni fomentará la secesión".

En este periodo (1998 - 2021), se han producido dos hechos nefastos que han menoscabado la soberanía e integridad territorial del Ecuador, así el 26 de octubre de 1998, el Presidente Jorge Jamil Mahuad Witt, firma en Brasilia, el denominado "Acuerdo de Paz" con el Perú, con lo que oficialmente el Ecuador reconoce el Protocolo de Río de Janeiro, renunciando a nuestros derechos territoriales sobre la cuenca del Amazonas y acepta el despojo territorial más inicuo que registra la historia del continente, reduciendo el territorio nacional a una superficie terrestre continental insular, de 270.670 kilómetros cuadrados.

Continuando con la vergonzosa historia de renunciamientos, en lo que corresponde al segmento marítimo e insular, el gobierno del Ecuador bajo la presidencia de Rafael Vicente Correa Delgado, resuelve la adhesión a la Convención de las Naciones Unidas sobre el Derecho del Mar (CONVEMAR), en julio del 2012, lo que significa renunciar a la tesis nacional de las 200 millas de mar territorial y aceptar un mar territorial de doce millas marinas de conformidad a lo estatuido en el art. 3 de CONVEMAR, quebrantando el mandato constitucional, ordenado en el art. 4 de la Constitución de la República, antes citado, que dispone "[...] El territorio del Ecuador es inalienable, irreductible e inviolable" y que ordena "[...] Nadie atentará contra la Unidad territorial ni fomentará la secesión.", aceptando la pérdida de 1'095.445 kilómetros cuadrados de mar territorial, $857.445 \mathrm{~km} 2$, correspondiente al segmento insular y $238.000 \mathrm{~km} 2$, al segmento continental, según los límites establecidos en artículo 628 del Código Civil Ecuatoriano.

Pronunciamientos del Estado ecuatoriano que fundamentan la tesis soberana de las doscientas millas de mar territorial.

A continuación, los Instrumentos Internacionales suscritos por los gobiernos de Chile, Ecuador y Perú en Santiago de Chile el 18 de agosto de 1952, aprobados y ratificados por el Estado Ecuatoriano.

\section{Declaración de Santiago (Declaración sobre Zona Marítima 18 de agosto de 1952)}

Los gobiernos de Ecuador, Chile y Perú, en la declaración de Santiago de Chile de 1952, que fuera ratificada por el gobierno ecuatoriano, mediante decreto ejecutivo No. 275, promulgado en el RO No. 1029 de 24 de enero de 1956, declaran que "[...] es su deber cuidar de la conservación y protección de sus recursos naturales y reglamentar el aprovechamiento de ellos a fin de obtener las mejores ventajas para sus respectivos países.", sobre "fuentes insustituibles de subsistencia y de recursos económicos que les son vitales [...]", por lo que proclaman "[...] como norma de su política internacional marítima, la soberanía y jurisdicción exclusivas que a cada uno de ellos corresponde sobre el mar que baña las costas de sus respectivos países, 
hasta una distancia mínima de 200 millas marinas desde las referidas costas.", que "incluye también la soberanía y jurisdicción exclusivas sobre el suelo y el subsuelo que a ella corresponde", y que "En el caso del territorio insular, la zona de 200 millas marinas se aplicará en todo el contorno de la isla o grupo de islas.", asumiendo la soberanía y jurisdicción exclusivas "[...] sobre el mar que baña las costas de sus respectivos países, hasta una distancia mínima de 200 millas marinas desde las referidas costas y sobre el suelo y subsuelo, que ha dicha zona marítima corresponde, inclusive el espacio aéreo que gravita sobre aquella".

Convenio Complementario a la Declaración de Soberanía sobre la Zona Marítima de 200 Millas.

Los Gobiernos de las Repúblicas de Chile, Ecuador y Perú, de conformidad con lo acordado en la Resolución $N^{\circ}$ X, de 8 de octubre de 1954, suscrita en Santiago de Chile por la Comisión Permanente de la Conferencia sobre Explotación y Conservación de las Riquezas Marítimas del Pacífico Sur, considerando que: "Chile, Ecuador y Perú han proclamado su soberanía sobre el mar que baña las costas de sus respectivos países, hasta una distancia mínima de 200 millas marinas, desde las referidas costas, incluyéndose el suelo y subsuelo que a esa Zona Marítima corresponde [...]" convienen que: "Procederán de común acuerdo en la defensa jurídica del principio de la Soberanía sobre Zona Marítima hasta una distancia mínima de 200 millas marinas, incluyéndose el suelo y el subsuelo respectivos.", manifiestan en la resolución que "[...] se obligan, asimismo, a prestarse la más amplia cooperación para una defensa común"; y se comprometen a "No celebrar convenios, arreglos o acuerdos que signifiquen menoscabo de la Soberanía de la zona referida".

Decreto Supremo de la Junta Militar de Gobierno, de Aprobación y Ratificación de los convenios suscritos por los Países Signatarios del Pacífico Sur, (Decreto No. 2556 promulgado en el RO. 376 de 18 de noviembre de 1964).

La Junta Militar de Gobierno mediante Decreto Supremo No. 2556 promulgado en el RO. 376 de 18 de noviembre de 1964; aprueba y ratifica el Convenio Complementario a la Declaración de soberanía sobre Zona marítima de 200 Millas; sobre Zona Especial Fronteriza Marítima, y sobre las Medidas de Vigilancia y Control de las Zonas Marítimas de Países Signatarios del Pacífico Sur, considerando que son instrumentos internacionales que "[...] guardan íntima vinculación con la protección de los intereses económicos y pesqueros del país; al mismo tiempo, reafirman la jurisdicción y soberanía del Ecuador en la zona marítima que inclusive, cubre el suelo y subsuelo que a ella corresponde.", y considerando que tales Convenios "[...] proclaman como norma de política internacional marítima conjunta la conservación de los recursos naturales, a la vez que obligan a impedir que la explotación foránea de tales bienes ponga en peligro la existencia, integridad y conservación de estas riquezas, en perjuicio de los pueblos que, por su posición geográfica, poseen en sus manos fuentes insustituibles de subsistencia y de recursos económicos que les son vitales."

Decreto No. 959-A, dictado por José María Velasco Ibarra, presidente de la República, RO. 265 de 13 de julio de 1971, que determina las líneas de base rectas desde la que debe medirse la anchura del mar territorial ecuatoriano.

En cumplimiento de la disposición del art. 628 del Código Civil que establece, que "[...] el mar territorial Ecuatoriano se medirá tanto en el territorio continental como en el Archipiélago de Colón (Islas Galápagos); desde la línea de base rectas que para el efecto se señalarán por Decreto Ejecutivo"; y, del estudio para el trazado de esas líneas y su trayectoria aprobado por los Ministerios de Relaciones Exteriores y de Defensa Nacional, el Presidente de la República Dr. José maría Velasco Ibarra, mediante decreto ejecutivo No. 959-A, publicado en el RO. 265 de 13 de julio de 1971, 
aprueba las líneas de base rectas para medir la anchura del mar territorial de la República "[...] por considerar que satisface a los intereses nacionales y se halla conforme en todo con las normas de derecho internacional vigentes sobre la materia".

Proyectos de Artículos para una Convención Multilateral sobre el Derecho del Mar.

Esta propuesta fue presentada por Ecuador con el patrocinio de otros países latinoamericanos ante la comisión de los Fondos Marinos de las Naciones Unidas, reunida en Nueva York, en agosto de 1971, declarando que "La soberanía del Estado ribereño, y por consiguiente el ejercicio de su jurisdicción, se extiende al mar adyacente a sus costas hasta límites que no excedan la distancia de 200 millas náuticas medidas a partir de las líneas de base aplicables", manifestando que la soberanía y jurisdicción se extienden al espacio aéreo situado sobre el mar adyacente y al suelo y subsuelo de esta última.

Posición del Ecuador en la III Conferencia de las Naciones Unidas sobre el Derecho del Mar, formulada en Caracas, el 8 de julio de 1974.

El Embajador Luis Valencia Rodríguez, Jefe de la Delegación del Ecuador, en la III Conferencia de las Naciones Unidas sobre el derecho del Mar, realizada en Caracas, el 8 de julio de 1974, en forma concluyente manifiesta, que "[...] la posición del Ecuador en materia del Derecho del Mar ha oído invariable y es perfectamente conocida", recapitulando "Mi país tiene soberanía y jurisdicción sobre el mar adyacente a sus costas hasta la distancia de 200 millas náuticas, a partir de las líneas de base aplicables", refiere que "El 18 de agosto de 1952, Ecuador, Perú y Chile, al suscribir la histórica Declaración de Santiago, proclaman como norma de su política internacional marítima, la soberanía y jurisdicción exclusivas que a cada uno de ellos corresponde sobre el mar que baña sus costas... hasta una distancia de 200 millas marinas, así como la soberanía y jurisdicción exclusivas sobre el suelo y subsuelo que a dicha zona corresponden". , denunciando a continuación "[...] las incursiones de barcos piratas, que pretendiendo desconocer nuestros derechos, han llegado a las aguas ecuatorianas con el objeto de saquear nuestras riquezas [...]", "[...] enfatizando una dura y desigual batalla [...]" "[...] porque el Ecuador es un país pequeño en desarrollo y las flotas pesqueras extranjeras han sido de países grandes, industrializados y poderosos, pese a lo cual el Ecuador ha ejercido... soberanía y jurisdicción efectivas en la zona de su mar adyacente de 200 millas.", finalmente el Canciller ecuatoriano ratifica que, "El Ecuador no aceptará una Convención que, de alguna manera, menoscabe la integridad de sus derechos sobre los recursos renovables y no renovables en la zona de 200 millas y defenderá estos recursos, no solo porque le pertenecen, sino porque el futuro del país está íntimamente ligado a su racional aprovechamiento".

\section{Presentación del Proyecto Ecuatoriano sobre Mar Territorial, el 16 de julio de 1974 en Caracas.}

El Doctor Luis Valencia Rodríguez, Jefe de la Delegación del Ecuador en su intervención a propósito de presentar el Proyecto Ecuatoriano en la A/CONF. 62/C. 2/L. 10 sobre Mar Territorial, realizada en caracas el 16 de julio de 1974, ratifica la posición del Estado ecuatoriano en una propuesta contenida en dos artículos que formula, "La soberanía del Estado ribereño se extiende más allá de sus costas y sus aguas interiores o archipiélagas a una zona adyacente denominada mar territorial.", que "La soberanía también se extiende al suelo y subsuelo del mar territorial así como al espacio aéreo correspondiente", y que "Todo Estado ribereño tiene el derecho a determinar la anchura de su mar territorial hasta una distancia no mayor de 200 millas náuticas, medidas desde las líneas de base aplicables." 
Presentación del Proyecto de Artículos sobre el Mar Territorial de 200 Millas presentada en la Sesión efectuada en Ginebra, Suiza, el 2 de mayo de 1975.

En su Intervención el Doctor Luis Valencia Rodríguez, jefe de la Delegación del Ecuador en la sesión formal de la Segunda Comisión, realizada en Ginebra, el 2 de mayo de 1975, presenta un proyecto de artículos sobre los derechos del mar, en los que destaca que los elementos esenciales del proyecto responden a una concepción "territorialista". enfatizando que, "[...] para muchos países y ciertamente para el Ecuador, la concepción de un mar territorial de esta naturaleza y de tal extensión no es una elucubración teórica ni constituye una aspiración hacia espacios de la alta mar, sino que responde a una realidad existente, a un derecho actual y vigente que en ningún caso ni pueden ni deben renunciar [...]", para luego revelar, "Fácil es deducir que quienes se oponen a una concepción de esta naturaleza son las grandes potencias, acostumbradas como han estado a establecer, ellas sí, en forma unilateral y omnímodamente, las normas que han querido en materia del Derecho del Mar, normas que les han permitido la explotación irracional de los mares ajenos. Tal situación debe terminar de una vez para siempre. El proyecto que presentó tiende a esta finalidad y a asegurar permanentemente los derechos de los Estados en vías de desarrollo en el mar territorial de hasta 200 millas". A/CONF. 62/C. 2/L.88, Ginebra 2 de mayo 1975.

Resoluciones para la aprobación y suscripción de la "Convención de las Naciones Unidas sobre el Derecho del Mar (CONVEMAR)".

La Corte Constitucional para el Período de Transición, según le faculta el numeral 1 del Art. 438 de la Constitución de la República, mediante Dictamen 007-11-DTI-CC, de 01 de septiembre de 2011, se pronuncia favorablemente a la adhesión del Ecuador a la Convención de las Naciones Unidas sobre el Derecho del Mar (CONVEMAR).

La Asamblea Nacional, el 22 de mayo del 2012, con 81 votos a favor, 9 votos en contra y 12 abstenciones, resuelve aprobar la Convención de las Naciones Unidas sobre el Derecho del Mar (CONVEMAR).

El Ecuador se adhiere a CONVEMAR, según Decreto Ejecutivo No.1238 publicado en el RO. 759 de 02 de agosto de 2012, dictado por el presidente Constitucional de la República del Ecuador, Rafael Vicente Correa Delgado.

Normas constitucionales y legales que vulnera la adhesión a la Convención de las Naciones Unidas sobre el Derecho del Mar (CONVEMAR).

El presidente de la República, Rafael Vicente Correa Delgado, La Corte Constitucional de "Transición" y la Asamblea Nacional, al aprobar la CONVEMAR, vulneran la Constitución y la Ley, así:

La adhesión a CONVEMAR, viola el art. 4 de la Constitución de la República del Ecuador vigente, que dispone que "El territorio del Ecuador constituye una unidad geográfica" y que el territorio "[...] es inalienable, irreductible e inviolable", al aprobar y ratificar La CONVEMAR, con pleno conocimiento y voluntad, admiten que la Anchura del mar territorial ecuatoriano, "[...] no exceda de 12 millas marinas medidas a partir de las líneas de base determinadas de conformidad con la Convención [...]" según lo dispone el art. 3, mutilando y reduciendo el mar territorial en 188 millas, atentando así contra la unidad territorial y soberanía del Ecuador.

Se inobserva lo dispuesto en el art. 609 del Código Civil vigente, que consigna entre los bienes nacionales"[...] El mar adyacente, hasta una distancia de doscientas millas marinas, medidas desde los puntos más salientes de la costa continental ecuatoriana y los de las islas más extremas del Archipiélago de Colón y desde los puntos de la más baja marea, según la línea de base que se señalará por Decreto Ejecutivo, así como, el lecho y el subsuelo del mar adyacente." y violan el art. 610 de 
la misma normativa que dispone "[...] Es igualmente de dominio nacional el espacio aéreo correspondiente al territorio del Estado, incluido en este el Mar Territorial definido en el artículo anterior.", por lo que al reducir de 200 a 12 millas el mar territorial han violado la Constitución y la Ley atentando contra los bienes que constituyen el patrimonio nacional.

Violan el art. 422 de la Constitución que prescribe "No se podrá celebrar tratados o instrumentos internacionales en los que el Estado ecuatoriano ceda jurisdicción soberana a instancias de arbitraje internacional, en controversias contractuales o de índole comercial, entre el Estado y personas naturales y jurídicas privadas", cuando según lo estatuido en el art. 287 de la CONVEMAR "[...] al firmar o ratificar la Convención o al adherirse a ella, o en cualquier momento ulterior los Estados podrán elegir libremente, mediante una declaración escrita", que de conformidad a la declaración de la Asamblea Nacional, puede ser el "Tribunal Internacional del Derecho del Mar"; "La Corte Internacional de Justicia"; o "Un Tribunal Especial de conformidad con el anexo VIII" de la Convención, para la solución de las controversias "[...] cediendo jurisdicción en las controversias relacionadas con pesquerías, protección y preservación del medio marino, investigación científica marina, y navegación, incluida la contaminación causada por buques y su vertimiento [...]", lo cual es contrario a la disposición constitucional.

Contravienen el art. 424 de la Constitución que prevalece sobre cualquier otra del ordenamiento jurídico, y obliga que las normas y los actos del poder público mantengan conformidad con las disposiciones constitucionales, en caso contrario carecerán de eficacia jurídica, norma constitucional que han transgredido al reducir, mutilar y ceder 188 millas del mar territorial ecuatoriano, a los intereses de las grandes potencias depredadoras de los mares.

\section{Evocación patriótica sobre la soberanía nacional e integridad territorial}

Históricamente el Ecuador ha sido víctima de una política exterior pusilánime y desacertada que junto a una "pobre" conducción en la defensa militar, ha derivado en una serie de mutilaciones al territorio nacional.

La lacerante y trágica historia de afectaciones a la integridad territorial inicia en la Real Audiencia de Quito, origen de nuestra nacionalidad, inicia con un país de 3’765.240 kilómetros cuadrados de superficie, hoy reducida a un "pequeño" país con una extensión territorial de $270.670 \mathrm{~km}^{2}$, cuando el Presidente Jamil Mahuad Witt, firma el 26 de octubre de 1998, el Acta de Brasilia, por el cual se formalizó el mal llamado "acuerdo de paz" entre Ecuador y Perú, que derivó en la demarcación de los 78 kilómetros de frontera en la Cordillera del Cóndor y el renunciamiento a la tesis soberana del pueblo del Ecuador que proclamara la nulidad del protocolo de Río de Janeiro de 1942.

Pero como si no fuera suficiente la desmembración del territorio continental, como lo presagiara el historiador y Ex-canciller de la República, Dr. Jorge Salvador Lara, en su obra "Reflexiones sobre el Nuevo Derecho del Mar", que por "coincidir con su pensamiento", también reproduce Fernando Pavón Egas (1988) en su obra "Problemas de Soberanía Territorial y Limítrofe del Ecuador", quien alerta

que hay agentes descarados, descastados, dijéramos: en todas partes hay, lamentablemente, gentes de muy mala arcilla, de las que suelen servirse las naciones imperialistas como "cipayos" o "quislings", que vehementemente ansían, sueñan contra sus convicciones, se vea reducida la soberanía marítima del Ecuador, de 200 millas, en sus ámbitos continental e insular, a un ínfimo mar territorial de 12 millas, a pretexto de que nuestra posición jurídica, establecida en la Constitución de la República y en el Código Civil es "extremadamente territorialista", y que debe el país 
allanarse a esa mínima extensión marítima en homenaje genuflexo al designio de las grandes potencias, especialmente de los Estados Unidos de Norteamérica, que han logrado consagrar esa insignificante, anti científica y anti geográfica anchura en la Convención Sobre el Derecho del Mar, labrada rabulescamente al amparo de la Organización de las "Naciones Unidas" y al alto costo de la maquiavélica división de los países del tercer mundo. (p.139).

Así se revela una de los escenarios más penosos para el pueblo y la patria, los principios de soberanía e independencia nacional a más de los enemigos externos, tiene detractores internos que para desgracia nacional han operado desde las principales funciones del poder político del Estado, logrando sus nefastos despropósitos.

\section{CONCLUSIONES}

La tesis proclamada y defendida por el Estado ecuatoriano, de un mar territorial de 200 millas náuticas, concebida como una zona adyacente al territorio del Estado costero, donde este ejerce soberanía y jurisdicción exclusiva, fue asumida como una posición nacional, desde el 18 de agosto de 1952, en que el Ecuador junto con Chile y Perú, hicieron uso del derecho a determinar su mar territorial en doscientas millas náuticas, conforme la Declaración de Santiago.

Con la adhesión del Ecuador a la Convención de las Naciones Unidas sobre el Derecho del Mar (CONVEMAR), marco jurídico regulatorio de la actividad en los mares, que establece un mar territorial de doce millas en las cuales el Estado suscriptor, ejercerá su jurisdicción y competencia soberana, el Ecuador hace un renunciamiento expreso a la tesis de soberanía y jurisdicción del Ecuador sobre las 200 millas de mar territorial con lo cual cede 188 millas de mar territorial, renunciando a una fuente de inmensos recursos naturales y a la riqueza ictiológica alimentaria más importante para el progreso y desarrollo de nuestro pueblo y nación.

Al aprobar y ratificar CONVEMAR, el Presidente de la República, Rafael Vicente Correa Delgado, La Corte Constitucional de "Transición" y la Asamblea Nacional del año 2012, lo hacen violando el ordenamiento jurídico nacional y ceden la soberanía y dominio que sobre las 200 millas de mar territorial el Ecuador venía sosteniendo como tesis nacional, afectación comparable a la firma del Protocolo de Río de Janeiro en la presidencia de Carlos Alberto Arroyo del Río, y la firma del "Acuerdo de Paz" con el Perú, firmado el 26 de octubre de 1998, por Jamil Mahuad Witt, con lo que oficialmente el Estado ecuatoriano acepta el Protocolo de Río de Janeiro y la nefasta mutilación territorial a nuestro territorio, por lo que, CONVEMAR y los demás tratados lesivos a la soberanía nacional deben ser revisados.

\section{REFERENCIAS}

Decreto Ejecutivo No. 2890 de 2002. Creación de la Comisión Nacional sobre el Derecho del Mar como un organismo adscrito a la Presidencia de la República. 29 de julio de 2002. Registro Oficial 628.

Corte Constitucional. Dictamen N.ํ 007-11-DTI-CC, Caso N.ํ 0023-10-TI; 1 de septiembre del 2011.

Resolución Legislativa No. 00 de 2012 [Asamblea Nacional]. Aprobación de la Convención de las Naciones Unidas sobre el Derecho del Mar (CONVEMAR) con la Declaración del Ecuador al momento de adherir a la Convención de 
Naciones Unidas sobre el Derecho del Mar. 1 de Junio del 2012. Registro Oficial Suplemento 715.

Decreto Ejecutivo No. 1238 de 2012. Ratificación de la Convención de las Naciones Unidas sobre el Derecho del Mar CONVEMAR. 2 de agosto de 2012. Registro Oficial 759.

Declaraciones oficiales, exposiciones a la prensa nacional, discursos, conferencias e informes del Dr. Luis Valencia Rodríguez, Presidente de la Delegación del Ecuador a la Tercera Conferencia de las Naciones Unidas sobre el Derecho del Mar. (Etapas Caracas, 1974, Ginebra, 1975, Nueva York, 1976)

La Primera Conferencia de las Naciones Unidas sobre el Derecho del Mar, Ginebra, 1958. Volumen III, pág. 33. Documentos oficiales. Public

La Segunda Conferencia de las Naciones Unidas sobre el Derecho del Mar, Ginebra, 1960. Actas resumidas de las Sesiones Plenarias y de las Sesiones de la Comisión Plenaria. Págs. 120 y 121. Documentos Oficiales. Publicaciones de las Naciones Unidas.

Salvador, J. (1980). Reflexiones sobre el Nuevo Derecho del Mar. Editorial Universitaria.

Pavón, F. (1978). Mar territorial de 200 millas y mar patrimonial. Quito: Editorial Universitaria.

Pavón, F. (1984). El Ecuador en la Tercera Conferencia de las Naciones Unidas sobre el Derecho del Mar. Quito: Editorial Universitaria.

Pavón, F. (1988). Los Problemas de Soberanía Territorial y Limítrofe del Ecuador. Quito: Editorial Universitaria

Resoluciones de la Asamblea General de las Naciones Unidas. 1105 (XI), 1307 (XIII), 2340 (XXII-1967), 2467 A, B, C y D. (XXIII-1968), 2574 (XXIV -1969), 2749 y 2750 (XXV-1970), 3067 (XXVIII-1973).

Vargas, E. (1973). América Latina y los problemas contemporáneos del derecho del mar. Editorial Andrés Bello. 